\title{
Severe Anorexia in a Child with Arachnoid Cyst
}

\author{
RAMONA MIHAELA NEDELCUTA ${ }^{1}$, VLAD DUMITRU BALEANU1*, DRAGOS VIRGIL DAVITOIU3, \\ TIBERIU STEFANITA TENEA COJAN ${ }^{4}$, COSMIN ALEXANDRU CIORA ${ }^{5}$, GIGI CALIN ${ }^{1}$ \\ ${ }^{1}$ University of Medicine and Pharmacy of Craiova, Pediatrics Department, 2 Petru Rares Str., 200349, Craiova, Romania. \\ ¿University of Medicine and Pharmacy of Craiova, Surgery Department, Clinical Emergency Hospital St. Pantelimon Bucharest, \\ 340-342 Pantelimon Road, 021659, Bucharest, Romania. \\ ${ }^{3}$ University of Medicine and Pharmacy of Bucharest, Surgery Department, Clinical Emergency Hospital Sf. Pantelimon Bucharest, \\ 340-342 Pantelimon Road, 021659, Bucharest, Romania. \\ ${ }^{4}$ University of Medicine and Pharmacy of Craiova, Department of Surgery, CFR Hospital of Craiova, Stirbei-Voda Str., 200374, \\ Craiova, Romania
}

\begin{abstract}
The G.V. 5 year and 11 months old boy, accused anorexia, headache with left hemicrany with onset of about 2 weeks. The only conclusive anamnestic aspect is a cranio-cerebral trauma that occurred 2 months before the onset of the symptomatology. The child was completely clinical, laboratory, imaging examined. There were no somatic changes or biological parameters. In diagnostic imaging, CT reveals a temporoparietal arachnoid cyst without deformation of the ventricular system of $5.5 / 4.5 \mathrm{~cm}$. The postoperative evolution of the case is unsatisfactory, 2 months after surgery the child develops iatrogenic epilepsy, behavioral disorders with anxiety, anxious syndrome and severe anorexia, refractory to treatment, as well as neurological manifestations - transient hemiparesis. We mention the issue of certainty indication for surgical intervention in a case of arachnoid cyst and the possibility of impairment and/or damage to the hypothalamus as control of hunger, satiety or damage at the level of synaptic transmission.
\end{abstract}

Keywords: anorexia, arachnoid cyst, ventricular system

A decreased appetite can have countless causes. Anorexia is the condition characterized by the loss of desire to ingest food, which is a symptom of various disorders or as a component of a food behavior with psychosomatic and neuroendocrine disorder [1].

At children, fever, infectious disease, cachexia, renal or chronic heart disease are associated with anorexia, as a symptom associated with the underlying clinical aspect. Duration of disease is a variable parameter, anorexia resolves with the onset of acute disorders with nutritional recovery over time, if any, or persists and eventually worsens during chronic, cachexia, oncological conditions.

There are also rare cases of anorexia that may be the only sign of onset, sometimes remaining the only symptom and requiring additional investigations. Such a possibility may be the arachnoid cyst. Arachnoid cyst is the most common cystic anomaly in the brain. It represents $1-2 \%$ of the intracranial masses. Often it is a casual discovery in the first decades of life due to the widespread use of reliable imaging $\mathrm{CT}$ and MRI methods.

The frequency is described as higher in boys and in the left hemisphere without an objective cause [1].

Most of them remain asymptomatic throughout their lives, few becoming clinically noisy.

There seems to be a trigger focus that transforms an asymptomatic congenital cyst into a clinical case. Supervision of the small child is compulsory for the family. Avoiding trauma can be crucial for the onset of a condition.

\section{Experimental part}

Methods and materials

The G.V., 5 year and 11 months old boy accused anorexia, headache with aspect of left hemicrania with approximately 1 month onset. It is the 2 nd child born via caesarean section.
The mother is diagnosed with positive HBV during pregnancy. The boy has a sister with ITT with recurrent purple episodes. The patient suffers a head injury by falling and after 2 months presents the neurological signs of HIC, and headache.

The complete blood count, VSH, PCR, pharyngeal and nasal exudate test, ALT, AST, urea, creatinine, calcemia, magnesia, urinalysis, stool parasitic exam, were all within normal range. The ophthalmological assessment presents normal relationships without papillary edema or indirect signs of HIC.

An EEG test shows normal tracing without paroxysmal discharge. The neurological examination shows a normal temporospatial orientation, normal cranial nerve examination.

A CT scan shows a $4.5 / 5.5 \mathrm{~cm}$ left temporal arachnoid cyst without posttraumatic lesions. (Fig. 1). Cerebral MRI confirms the diagnosis of anterior left frontotemporoparietal arachnoid cyst with symmetrical ventricular system and the rest of brain structures in normal limits.

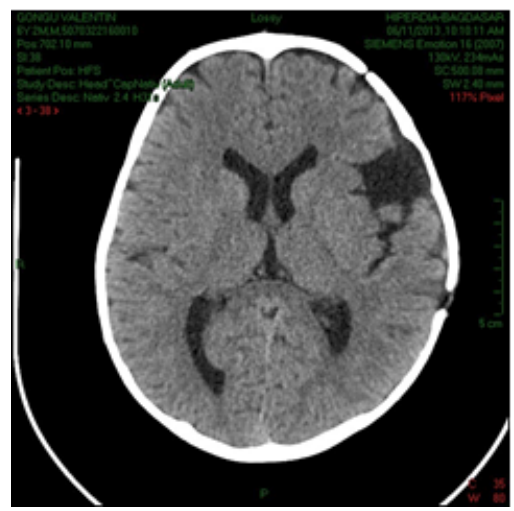

Fig. 1.

CT scan shows a 4.5/5.5 $\mathrm{cm}$ left temporal arachnoid cyst

\footnotetext{
*email: baleanuvlad@gmail.com; Phone: 0040765865886
} 
After one month postoperative CT shows the presence of an anterior left temporal fluid cystic mass of $5.5 / 3.75 \mathrm{~cm}$, with regional atrophy of the insular cortex. (Fig. 2).

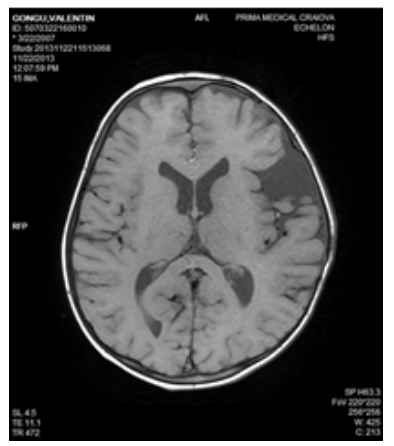

Fig. 2. CT scan after one months

10 months after surgery, the dimensions reached 5.5/ $6.9 \mathrm{~cm}$ with subarachnoidian left temporal pole shape, which was inserted in the left sylvian fissure with minimal mass effect on the middle left artery. (Fig. 3). 5 years after intervention, MRI reveals $6.3 / 4.5 / 7.6 \mathrm{~cm}$ temporoparietal cyst, versus $5.5 / 4.4 \mathrm{~cm}$ initially, with mass effect on temporal lobes, frontal and left parietal, inserted at the level of sylvian fissure, with the cranial deformation in the left temporoparietal area, dilatation of the basal cistern and ventricular system, cortical gliolysis, right temporal lobe hypotrophy. (Fig. 4).

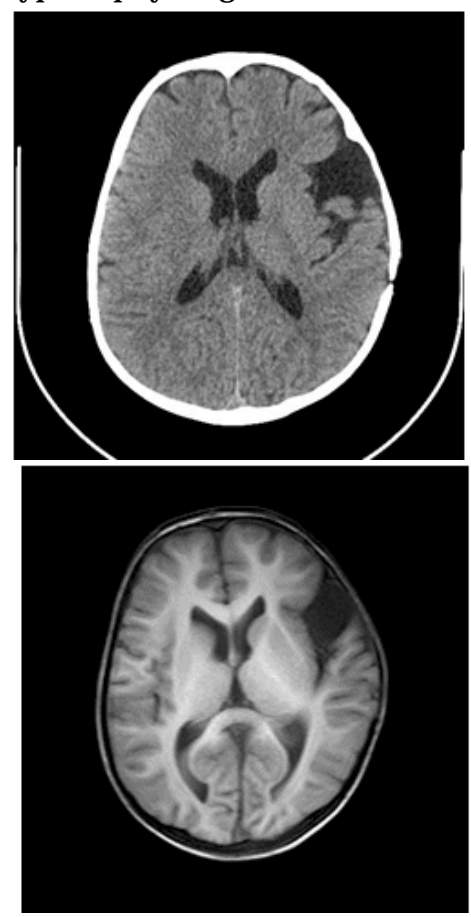

Fig. 3. CT scan 10 months after surgery

Fig. 4. MRI after 5 years

\section{Results and discussions}

The postoperative evolution of the case is unsatisfactory, after 2 months the child develops iatrogenic epilepsy, behavioral disorders with anxiety, anxious syndrome and severe anorexia, refractory to treatment, as well as neurological manifestations - transient hemiparesis.

According to the medical literature, the most frequent localization of arachnoid cysts is the temporal or parietal region mostly at the insertion of the sylvian fissure [3-6].

Food behavior presents a complex regulation, nervous, endocrine, even genetic and involves the intervention of limbic, paralimbic structures and increased attention on the hypothalamus where there are two centers of hunger and satiety in the lateral and ventromedial hypothalamus respectively [7-9]. Hormones - leptin, ghrelin, insulin, interfere in nutritional balance, and the cultural, psychological environmental factors create the general climate on which the disorders appeared $[10,11]$.

\section{Conclusions}

The patient's biological status is altered, with current diagnoses being: Severe anorexia. Hypotrophy. Secondary anemic syndrome. Iatrogenic epilepsy. Spasmophilia. Impaired seizures. Transient hemiparesis. Recurrent left frontotemporoparietal cyst. The evolution of the patient raises other questions: How do we decide on the convenience of surgery? An arachnoid cyst (congenital or non-congenital) should be drained or treated conservatively, so CT scan should be repeated? An asymptomatic cyst becomes symptomatic noisy under a trigger factor? Does the reintervention is mandatory, with any risk, taking into account the associated pathology? Is it possible to recreate the summation of the mass effect on the surrounding structures under the conditions of effective cyst drainage?

Does the complex hypothalamic impairments or synaptic neurotransmitter impairments, would explain severe anorexia and paroxysmal, epileptogenic discharges? How can the neurosomatic status of the patient be modulated at the moment? What is the prognosis of the case, whether it is curable or not, at the current stage of medical development? Is it impotant to initiate a pediatric palliative care or can be attempted a curative surgery? Is it a particular form of iatrogenic epilepsy, normally in the literature and the crises occur prior to surgery and are stopped after drainage? Is it necessary a complex medical team involving pediatric, neurosurgeon, neurologist for the patient recovery?

\section{References}

1.BROW N CE AND NICHOLSON K, Cognitive behavioural therapy for eating disorders: how do clinician characteristics impact on treatment fidelity? J Eat Disord. 2018; 6: 19.

2.SPETTIGUE W, NORRIS LM, SANTOS A AND OBEID N, Treatment of children and adolescents with avoidant/restrictive food intake disorder: a case series examining the feasibility of family therapy and adjunctive treatments, J Eat Disord. 2018; 6: 20.

3.PATINO LD, YUDCHAK CG, BARBIERI DP, STRAMESI J M, CHAMPAGNE V AND RAMUNDO MP, Comparative Study on the Effectiveness Between Intensive Outpatient Care and Partial Hospitalization Treatments in Patients Diagnosed with Eating Disorders, Archives of medicine, 2018, Vol.10 No.1:9, p.1-11.

4.DANIEL PM, Anatomy of the hypothalamus and pituitary gland, J Clin Pathol Suppl (Assoc Clin Pathol) 1976; 7: p.1-7.

5.BIRAN J, TAHOR M, WIRCER E, AND LEVKOWITZ G, Role of developmental factors in hypothalamic function, Front Neuroanat. 2015; 9: 47.

6.GOSHU E, JIN H, LOVEJOY J, MARION J F, MICHAUD JL, FAN CM., Sim2 contributes to neuroendocrine hormone gene expression in the anterior hypothalamus. Mol Endocrinol. 2004 May; 18(5): p.125162.

7.ZHAO L, KIM WK, IKEDA Y, ANDERSON KK, BECK L, CHASE S, TOBET AS, PARKER LK, Central Nervous System-Specific Knockout of Steroidogenic Factor 1 Results in Increased Anxiety-Like Behavior, Mol Endocrinol. 2008 J un; 22(6): p.1403-1415.

8.LU J, ZHU XL, Characteristics of distribution and configuration of intracranial arachnoid membranes. Surg Radiol Anat. 2005 Dec; 27(6): p.472-8.

9.EIDLITZ-MARKUS T, ZEHARIA A, COHEN YH, KONEN O., Characteristics and management of arachnoid cyst in the pediatric headache clinic setting. Headache. 2014 Nov-Dec; 54(10): p.1583-90. 10.LIU JK, COLE CD, KAN P, SCHMIDT MH, Spinal extradural arachnoid cysts: clinical, radiological, and surgical features.Neurosurg Focus. 2007 Feb 15; 22(2):E6. Review.

11.MAZURKIEWICZ-BEfDZINSKA M, DILLING-OSTROWSKA E., Presentation of intracranial arachnoid cysts in children: correlation between localization and clinical symptoms. Med Sci Monit. 2002 J un; 8(6):CR462-5.

Manuscript received: 28.08 .2019 